\title{
DIREITO DE RECESSO NAS SOCIEDADES LIMITADAS QUANDO OCORRE ALTERAÇÃO CONTRATUAL COM INCLUSÃO DE CLÁUSULA ARBITRAL
}

\section{Frederico de Andrade Gabrich ${ }^{1}$ Felipe Bartolomeo Moreira ${ }^{2}$}

Resumo: O presente artigo analisa o instituto do direito de recesso à luz do sistema normativo contemporâneo, entremeado por princípios e regras que devem conviver de forma harmônica no ordenamento, e verifica a sua aplicação às sociedades limitadas brasileiras, especificamente em razão de alteração contratual que inclua no documento uma cláusula compromissória ou arbitral. Utiliza-se o método hipotético dedutivo, tendo como marcos teóricos o Código Civil, a Lei 6.404/76 e na Lei n. 9.307/96.

Palavras-chave: Direito de Recesso; Sociedade Limitada; Cláusula Arbitral; Contrato Social; Alteração Contratual.

\section{THE RIGHT OF WITHDRAW IN LIMITED LIABILITY COMPANIES WHEN CONTRACTUAL AMENDMENT WITH INCLUSION OF ARBITRATION CLAUSE OCCURS}

\begin{abstract}
This article analyzes the right of withdrawal in light of the contemporary normative system, interspersed by principles and rules that must coexist in a harmonious way in the legal system, and verifies its application to Brazilian limited companies, specifically due to contractual alteration that includes arbitration clause. The hypothetical deductive method is used, having as theoretical frameworks the Civil Code, Law n. 6.404/76 and Law n. 9.307/96.
\end{abstract}

Keywords: Right of Withdraw; Limited Liability Companies; Arbitration Clause; Bylaws; Amendment of the Bylaws.

\section{INTRODUÇÃO}

No Brasil, a maioria das sociedades de natureza empresária são constituídas sob a forma de sociedade limitada, atualmente regida pelos artigos 1.052 a 1.087 do Código Civil.

Algumas controvérsias relativas às sociedades limitadas decorrem do disposto no artigo 1.053 do Código Civil, que prevê a possibilidade de regência supletiva dessas sociedades pelas normas que regulam as sociedades simples, ou, dependendo do disposto no

\footnotetext{
${ }^{1}$ Doutor em Direito pela Universidade Federal de Minas Gerais - UFMG, Minas Gerais (Brasil). Professor pela Universidade FUMEC - FUMEC, Minas Gerais (Brasil). Currículo Lattes: http://lattes.cnpq.br/9297224411224412 E-mail: frederico.gabrich@gmail.com.

${ }^{2}$ Mestrando em Direito pela Universidade FUMEC - FUMEC, Minas Gerais (Brasil). Professor pela Faculdade Pitágoras, Minas Gerais (Brasil). Currículo Lattes: http://lattes.cnpq.br/2824188302435174. E-mail: bartolomeo@bbaa.com.br.
} 
contrato social, pelas normas que regulam as sociedades por ações. A diferença de regulação determinada pelo Código Civil em relação ao disposto sobre um mesmo tema também previsto na lei que regula as sociedades por ações (Lei n. 6.404/76), acaba estabelecendo possibilidade de muitos questionamentos e dúvidas. É o que ocorre em relação às hipóteses que ensejam o exercício do direito de retirada (recesso), especialmente quando há mudança significativa do contrato social antes vigente.

Por isso, o presente estudo científico analisa o instituto do direito de recesso à luz do sistema normativo contemporâneo, entremeado por princípios e regras que devem conviver de forma harmônica no ordenamento, e verifica a sua aplicação às sociedades limitadas brasileiras, especificamente em razão de alteração contratual que inclua no documento uma cláusula compromissória ou arbitral.

A pesquisa também verifica se as normas que regulam as sociedades simples e a lei que rege as sociedades anônimas pode ser utilizada supletiva ou analogicamente para regular sociedades limitadas em casos específicos de inclusão de cláusula arbitral no contrato social.

Utiliza-se na pesquisa o método hipotético dedutivo, tendo como marcos teóricos, sobretudo, o disposto no Código Civil, na Lei 6.404/76 e na Lei n. 9.307/96.

\section{OS PRINCÍPIOS DA NORMATIVIDADE E DA AUTONOMIA PRIVADA}

A hermenêutica jurídica passou por mudanças significativa com o tempo, evoluindo do pensamento jusnaturalista para o positivista, e deste para o pós-positivista (FREITAS; MOREIRA, 2016, p. 1.694).

É certo que no primeiro momento (jusnaturalista) a religião estava intimamente ligada ao direito, de forma que o direito, em especial o positivado, apenas teria validade se estivesse em conformidade com o direito natural (COULANGES, 2006).

Em razão das atrocidades geradas pelo absolutismo dos monarcas que detinham o poder decorrente do suposto direito natural, as pessoas se rebelaram na França no final do século XVIII, o que acabou levando à Revolução Francesa e ao movimento de objetivação (positivista) do direito. Dessa maneira, o direito passou a ser compreendido a partir dos comandos normativos expressos estabelecidos nas leis, teoricamente emanadas pelo e para o povo.

Revista Brasileira de Direito Empresarial | e-ISSN: 2526-0235| Porto Alegre | v. 4 | n. 2 |

p. 58-78 | Jul/Dez. 2018 
Nessa época, a ideia que prevalecia era a de que para se evitar novos abusos do direito, as leis deveriam ser interpretadas de forma restritiva, praticamente literal, o que gerou a hermenêutica positivista.

O Positivismo foi muito difundido pelas ideias estabelecidas por diversos autores, com destaque para Bobbio (2003) e Kelsen (1991), sendo que este último apontava que os homens deveriam seguir as normas estabelecidas e feitas pelos próprios homens e todo o direito se limitava aos atos normativos postos (FREITAS; MOREIRA, 2016, p. 1689-1690).

Contudo, com o tempo, verificou-se que o Positivismo, apesar de importante para garantia da certeza e da segurança jurídica, era bastante limitado em sua capacidade de permitir a concatenação entre a evolução social e a evolução do direito, uma vez que muitas mudanças ocorridas na dinâmica da vida em sociedade não eram (e não são) imediatamente reproduzidas nos textos normativos presentes nas leis. Verificou-se, então, a incompletude do direito positivado, que não era aplicado de forma adequada a todas as pessoas e a todas as situações fáticas, pois muitas vezes a lógica de um sistema hierárquico, positivado e rígido, deixava lacunas que não eram preenchidas com as normas já postas de forma expressa na lei em um dado momento. Isso permitiu ao reconhecimento da necessidade de serem desenvolvidas, a partir do positivismo, novas teorias (pós-positivistas) de aplicação do direito, com destaque para os trabalhos apresentados por Friedrich Müller (1996), Habermas (1997), Alexy (2014) e Dworkin (2002).

Nesse sentido, Ronald Dworkin desenvolveu importante trabalho voltado para o reconhecimento da existência das regras e dos princípios nos ordenamentos, bem como da abertura dos sistemas jurídicos por meio dos princípios, os quais, respeitadas algumas condições, podem determinar, no caso concreto, a mudança do sentido e do significado da regra, visando atender, inclusive, as imposições decorrentes da evolução da vida social. Assim, segundo Dworkin:

Quando, então, um juiz tem permissão para mudar uma regra de direito em vigo? Os princípios aparecem na resposta de duas maneiras distintas. Na primeira delas, é necessário, embora não suficiente, que o juiz considere que a mudança favorecerá algum princípio; dessa maneira o princípio justifica a modificação. [...]

Porém, não é qualquer princípio que pode ser invocado para justificar a mudança; caso contrário, nenhuma regra estaria a salvo. É preciso que existam alguns princípios com importância e outros sem importância e é preciso que existam alguns princípios mais importantes que outros. Esse critério não pode depender das preferências pessoais do juiz, selecionadas em meio a um mar de padrões extrajurídicos respeitáveis, cada um deles podendo ser, em princípio, elegível. Se fosse assim, não poderíamos afirmar a obrigatoriedade de regra alguma. Já que,

Revista Brasileira de Direito Empresarial | e-ISSN: 2526-0235| Porto Alegre | v. 4 | n. 2 |

p. 58-78 | Jul/Dez. 2018 
nesse caso, sempre poderíamos imaginar um juiz cujas preferências, selecionadas entre os padrões extrajurídicos, fossem tais que justificassem uma mudança ou uma reinterpretação radical até mesmo da regra mais arraigada.

$\mathrm{Na}$ segunda maneira de considerar o problema, um juiz que se propões a modificar uma doutrina existente deve levar em consideração alguns padrões importantes que se opõem ao abandono da doutrina estabelecida; esses padrões são, na sua maior parte, princípios [...] (DWORKIN, 2002, p. 59-60).

Da mesma forma, Dworkin aponta a força normativa dos princípios ao denominar como "princípio um padrão que deve ser observado, não porque vá promover ou assegurar uma situação econômica, política ou social considerada desejável, mas porque é uma exigência de justiça, equidade ou alguma outra dimensão da moralidade" (DWORKIN, 2002, p. 36).

De qualquer maneira, no Brasil, como Travessoni demonstra, a construção teórica pós-positivista ainda constitui um processo que evolui em seu próprio ritmo no plano teórico (TRAVESSONI, 2007).

Todavia, a partir dos paradigmas estabelecidos por Bobbio (2003), Dworkin (2002) e pela Constituição de 1988, Gabrich chega a apontar, em uma perspectiva pós-positivista, que não é razoável se afirmar que hoje exista no Brasil um princípio propriamente dito da "legalidade", uma vez que a norma jurídica, para ser realmente uma norma jurídica, precisa existir (ser declarada expressa ou implicitamente pelas diversas fontes do direito: constituição, leis, jurisprudência, costumes, atos administrativos, contratos), ser válida (não ter sido revogada ou derrogada por outra norma existente no ordenamento) e eficaz (ser efetivamente reconhecida e admitida como norma de conduta pela sociedade). Daí a evolução do princípio da legalidade para o princípio da normatividade, segundo o qual ninguém é obrigado a fazer ou deixar de fazer alguma coisa, senão em virtude de norma jurídica existente, válida e eficaz (GABRICH, 2010).

Nesse diapasão, entender a lógica pós-positivista e o princípio da normatividade é importante para fundamentar e reconhecer a força e a importância do princípio da autonomia privada, especialmente no âmbito do direito empresarial societário.

De fato, no direito brasileiro, como acontece em diversos outros ordenamentos, também não é difícil reconhecer a existência de dois tipos de normas: as imperativas ou cogentes e as dispositivas. É certo que no primeiro tipo de norma (imperativa), todas as pessoas são obrigadas a seguir os comandos decorrentes dessas normas, porque resguardam os interesses fundamentais de uma sociedade. Por outro lado, o segundo tipo de norma 
(dispositiva) diz respeito apenas aos interesses das partes que estão diretamente vinculados àquela norma, de forma que elas podem abrir mão de sua aplicação (NADER, 2014, p. 106).

De outra maneira, Bulgarelli esclarece que a maior parte das normas jurídicas são imperativas e que o descumprimento delas implica a atribuição de uma sanção específica, mas também reconhece a existência de normas destituídas de sanção, "aquelas que os destinatários podem não seguir; sua função é completar ou substituir a vontade das partes" (BULGARELLI, 1992, p. 54).

De fato, a própria constituição brasileira descreve em seu artigo $5^{\circ}$, inciso II, que ninguém é obrigado a fazer ou deixar de fazer algo, senão em virtude de lei (BRASIL, 1988), devendo esta lei ser interpretada como norma no sentido mais amplo e não de regra posta. Este entendimento segue a ideia supra proposta do princípio da normatividade.

Assim, na perspectiva do direito privado, a Autonomia Privada se insere justamente neste locus, pois onde não existe proibição para determinado ato, há autorização (implícita) para praticá-lo.

Nesse sentido, Orlando Gomes aponta que está "na autonomia privada, o substrato do negócio jurídico. Ele é o instrumento que o direito oferece aos particulares para que disciplinem seus interesses e travem relações com o objetivo de compô-los" (GOMES, 1967, p. 67).

Percebe-se, então, que a Autonomia Privada permite às partes dos negócios jurídicos regularem seus atos quando não houver um impedimento normativo expresso, podendo criar o direito que melhor atenda aos seus interesses, sobretudo por meio das cláusulas contratuais.

Assim, as relações privadas, especificamente, são regidas pela lógica da autonomia privada, observados os limites do princípio da normatividade, em um ordenamento normativo estruturado por meio de princípios e de regras, que são estabelecidas pelas diversas fontes do direito, de acordo com uma perspectiva doutrinária e de interpretação cada vez mais póspositivista.

\section{CONVENÇÃO ARBITRAL}

A arbitragem é conceituada por Carlos Alberto Carmona da seguinte forma:

A arbitragem - meio alternativo de solução de controvérsias através da intervenção de uma ou mais pessoas que recebem seus poderes de uma convenção privada,

Revista Brasileira de Direito Empresarial | e-ISSN: 2526-0235| Porto Alegre | v. 4 | n. 2 |

p. 58-78 | Jul/Dez. 2018 
decidindo com base nela, sem intervenção estatal, sendo a decisão destinada a assumir a mesma eficácia da sentença judicial - é colocada à disposição de quem quer que seja, para a solução de conflitos relativos a direitos patrimoniais acerca dos quais os litigantes possam dispor (CARMONA, 2004, p. 51).

Percebe-se por este conceito que a arbitragem é um meio privado de resolução de conflitos, não sendo utilizado, em princípio, o Poder Judiciário para acertar direitos das partes envolvidas na questão apresentada para pacificação.

No entanto, não é qualquer conflito que pode ser resolvido por meio da arbitragem. A Lei n. 9.307/96, que regula a arbitragem no Brasil, dispõe em seu primeiro artigo que são necessários alguns requisitos/limites para utilização deste meio: as partes devem ser capazes e o direito a ser acertado deve ser patrimonial disponível (BRASIL, 1996a).

Nada obstante, observado os limites estabelecidos pelo princípio da Autonomia Privada, ninguém é obrigado a aceitar que seu direito seja resolvido por meio de arbitragem. No entanto, respeitados os requisitos e limites determinados pela legislação específica, a partir do momento em que a parte optar pelo procedimento da arbitragem, esta se torna obrigatória (pacta sunt servanda).

Todavia, vale sempre destacar, a arbitragem possui duas espécies: a institucional (ou administrada) e a avulsa (ou ad hoc).

$\mathrm{Na}$ primeira espécie (arbitragem institucional), as partes escolhem uma instituição que se dedica à atividade de arbitragem. Nesse caso, as partes se vinculam às regras procedimentais já estabelecidos no regulamento da Câmara Arbitral escolhida, que administrará o procedimento arbitral em todas as suas fases.

Na segunda espécie (arbitragem avulsa ou $a d$ hoc), as partes escolhem quem será(ão) o(s) árbitro(s) e, instaurado o procedimento, estes definirão como será estabelecido e conduzido o procedimento arbitral a ser adotado naquele caso específico.

Este pacto que prevê a resolução de conflitos por meio de arbitragem é chamado de convenção arbitral que, por sua vez, também possui duas espécies nos termos do artigo $3^{\circ}$ da Lei da Arbitragem (BRASIL, 1996a): cláusula arbitral (ou cláusula compromissória) e o compromisso arbitral (ou pacto arbitral).

\subsection{CLÁUSULA ARBITRAL}

Revista Brasileira de Direito Empresarial | e-ISSN: 2526-0235| Porto Alegre | v. 4 | n. 2 |

p. 58-78 | Jul/Dez. 2018 
Como mencionado antes, a convenção arbitral é um gênero que possui duas espécies, a cláusula arbitral e o compromisso arbitral.

A cláusula arbitral é acordada e estabelecida expressamente pelas partes de um negócio jurídico antes de existir um conflito, e, caso ele exista, passará a ser resolvido pela arbitragem, observadas as condições eventualmente definidas pelas partes na mencionada cláusula.

De fato, as cláusulas arbitrais são consideradas como "cláusulas cheias", quando a maioria dos requisitos mínimos fundamentais da arbitragem são predefinidos pelas partes na própria cláusula. Nesse caso, além de outros requisitos que as partes entenderem viáveis e necessários no caso concreto, a cláusula arbitral predetermina expressamente se a arbitragem será avulsa ou institucional, bem como o número de árbitros, o nome dos árbitros ou da Câmara Arbitral (no caso da arbitragem ser institucional), o local no qual será proferida a sentença, a legislação aplicável, a língua que será adotada no procedimento, a responsabilidade pelo pagamento das custas etc.

Nessa linha, de acordo com Scavone Júnior:

A cláusula arbitral cheia é aquela que contém os requisitos mínimos para que possa
ser instaurado o procedimento arbitral (as condições mínimas que o art. 10 da Lei de
Arbitragem impõe para o compromisso arbitral), como, por exemplo, a forma de
indicação dos árbitros, o local etc., tornando prescindível o compromisso arbitral.
Sendo assim, ao surgir o conflito, as partes não precisam firmar compromisso
arbitral e qualquer delas pode dar início ao procedimento arbitral (SCAVONE
JÚNIOR, 2018, p. 89).

Assim, quando todos estes requisitos mínimos necessários estão presentes na cláusula arbitral, ela é chamada de cláusula arbitral cheia. Por outro lado, se faltar ao menos um requisito fundamental para o procedimento, a cláusula arbitral será chamada de "cláusula vazia".

Dessa maneira, conforme Scavone Júnior:

A cláusula arbitral vazia (ou em branco) é aquela em que as partes simplesmente se obrigam a submeter seus conflitos à arbitragem, sem estabelecer, contudo, as regras mínimas para desenvolvimento da solução arbitral e, tampouco, indicar as regras de uma entidade especializada, tornando necessário, ao surgir o conflito, que as partes, antes de dar início à arbitragem, firmem, além da cláusula arbitral, um compromisso arbitral (SCAVONE JÚNIOR, 2018, p. 91).

Realmente, as cláusulas arbitrais vazias não são nulas, no entanto, faz-se necessário o preenchimento dos seus requisitos mínimos para se evitar prejuízo à condução lógica e ordenada da arbitragem. Por isso, quando a cláusula arbitral é vazia e as partes não 
conseguem chegar a um consenso quanto a eles, o Poder Judiciário deve ser acionado com o único intuito de preencher os requisitos, nos termos do artigo $7^{\circ}$ da Lei de Arbitragem (BRASIL, 1996a). Ainda assim, nesse caso, o Poder Judiciário não poderá se manifestar especificamente acerca do objeto do litígio que seria levado para a arbitragem, mas apenas sobre os requisitos necessários para a completude da cláusula arbitral.

\subsection{COMPROMISSO ARBITRAL}

A outra espécie de convenção arbitral é o compromisso arbitral, e este diferencia-se da cláusula arbitral sobretudo porque o conflito já está instaurado e as partes podem decidir resolver a questão por meio da arbitragem e não pelo Poder Judiciário.

Dessa maneira, segundo Scavone Júnior:

O compromisso arbitral nada mais é que a convenção de arbitragem mediante o qual as partes pactuam que o conflito já existente entre elas será dirimido através da solução arbitral e pode ser: a) Judicial, na medida em que as partes decidem colocar termo no procedimento judicial em andamento e submeter o conflito à arbitragem; e b) Extrajudicial, firmado depois do conflito, mas antes da propositura de ação judicial (SCAVONE JÚNIOR, 2018, p. 94-95).

Verifica-se, então, que o compromisso arbitral pode ser feito a qualquer momento depois de o conflito já ter se instalado e pode ser estabelecido antes da propositura de uma demanda no Poder Judiciário, para evitar um procedimento judicial ou, então, findar um procedimento judicial já iniciado, para que as partes possam abandonar a disputa judicial e resolver o conflito por meio da arbitragem.

Não obstante, em termos legais, para se celebrar um compromisso arbitral, deve-se seguir os requisitos descritos nos artigos $9^{\circ}$ e 10 da Lei n. 9.307/96, que estabelecem o seguinte:

Art. $9^{\circ}$. O compromisso arbitral é a convenção através da qual as partes submetem um litígio à arbitragem de uma ou mais pessoas, podendo ser judicial ou extrajudicial.

$\S 1^{\circ} \mathrm{O}$ compromisso arbitral judicial celebrar-se-á por termo nos autos, perante o juízo ou tribunal, onde tem curso a demanda.

$\S 2^{\circ} \mathrm{O}$ compromisso arbitral extrajudicial será celebrado por escrito particular, assinado por duas testemunhas, ou por instrumento público.

Art. 10. Constará, obrigatoriamente, do compromisso arbitral:

I - o nome, profissão, estado civil e domicílio das partes;

II - o nome, profissão e domicílio do árbitro, ou dos árbitros, ou, se for o caso, a identificação da entidade à qual as partes delegaram a indicação de árbitros;

Revista Brasileira de Direito Empresarial | e-ISSN: 2526-0235| Porto Alegre | v. 4 | n. 2 |

p. 58-78 | Jul/Dez. 2018 
III - a matéria que será objeto da arbitragem; e

IV - o lugar em que será proferida a sentença arbitral.

\subsection{VIABILIDADE DE INCLUSÃO DE CLÁUSULA ARBITRAL NO CONTRATO} SOCIAL

Realmente, as sociedades limitadas brasileiras constituídas a partir de 2003 são reguladas pelo Código Civil (BRASIL, 2002) e, relativamente aos assuntos não regulados especificamente nos artigos 1.052 a 1.087 do Código Civil, as sociedades limitadas continuam regidas pelo disposto no Decreto n. 3.708/19, que não foi revogado, mas apenas derrogado em relação aos temas tratados especificamente pelo Código Civil acerca das sociedades limitadas.

De forma geral, os contratos sociais das sociedades limitadas devem possuir uma estrutura com algumas cláusulas importantes ou necessárias, dentre as quais destacam-se as seguintes:

a) nome e qualificação dos sócios;

b) indicação do tipo societário em constituição;

c) nome social;

d) objeto social;

e) endereço da sede e das filiais (se for o caso);

f) prazo de duração da sociedade (determinado ou indeterminado);

g) capital social, expresso em moeda corrente e, se o capital social não estiver integralizado, o prazo e as condições de integralização;

h) responsabilidade dos sócios e a suas participações nos lucros e nos prejuízos;

i) data de encerramento do exercício social;

j) a(s) pessoa(s) natural(is) responsável(eis) pela administração da sociedade, bem como seu(s) poder(es), limitação(ões) e atribuição(ões);

k) declaração de inexistência de impedimento legal ao exercício das atividades do(s) administrador(es);

1) indicação de foro para solução de eventuais controvérsias societárias.

Além dessas cláusulas mínimas essenciais e necessárias à existência, validade e eficácia do negócio jurídico societário, os sócios têm liberdade para estabelecerem outras, adequadas não apenas às necessidades do modelo de negócio que será adotado pela empresa

Revista Brasileira de Direito Empresarial | e-ISSN: 2526-0235| Porto Alegre | v. 4 | n. 2 |

p. 58-78 | Jul/Dez. 2018 
de titularidade da sociedade, mas também às necessidades e desejos dos sócios. São as chamadas "cláusulas facultativas". Contudo, é importante ressaltar que uma cláusula facultativa não pode ser contrária à lei ou ao disposto nas cláusulas necessárias.

Dentre as cláusulas facultativas, em decorrência dos objetivos da presente pesquisa, destaca-se a cláusula arbitral, que pode ser estabelecida para prever a utilização da arbitragem na solução de controvérsias que venham a existir entre os sócios, estabelecendo-se, nesse caso, a indicação do foro apenas para as hipóteses de medidas de urgência, anulação ou execução de sentença arbitral.

Em regra, admite-se plenamente a possibilidade de inserção de cláusula arbitral nos contratos sociais, pois os direitos eventualmente discutidos e/ou reinvindicados pelos sócios na maioria das controvérsias que podem teoricamente existir são disponíveis e de natureza patrimonial.

Todavia, alguns autores, como Barbara Makant, apontam que existem questões controversas sobre a aplicação da arbitragem nas sociedades, em especial porque alguns desses direitos não seriam patrimoniais (MAKANT, 2005, p. 576).

Ocorre que, em última análise, os direitos possivelmente discutidos e decorrentes de uma relação jurídica societária são sempre disponíveis e de ordem eminentemente patrimonial, pois mesmo os direitos políticos, como os decorrentes do exercício do direito a voto, no final, afetam os interesses e o patrimônio dos sócios e/ou da própria sociedade. Daí o motivo pelo qual, nessa perspectiva, deve-se admitir a inclusão de cláusulas arbitrais nos contratos de sociedades.

E mais. Considerando os princípios da autonomia privada e da normatividade, não existe qualquer norma que impeça que uma cláusula arbitral seja inserida em um contrato social, para que os sócios tenham os seus eventuais futuros conflitos resolvidos por meio da arbitragem. Logo, se a inclusão de cláusula arbitral nos contratos sociais não é proibida, ela é permitida. Inclusive, vale destacar, em virtude da especificidade das questões societárias, geralmente a arbitragem se mostra mais interessante, dada a especificidade do conhecimento dos árbitros que podem ser escolhidos pelas partes para a resolução de eventuais conflitos entre os sócios.

Por tudo isso, inclusive, o Instituto Brasileiro de Governança Corporativa (IBGC) aponta no item 1.4 de seu código das melhores práticas de governança corporativa a seguinte recomendação:

Revista Brasileira de Direito Empresarial | e-ISSN: 2526-0235| Porto Alegre | v. 4 | n. 2 |

p. 58-78 | Jul/Dez. 2018 
Os conflitos entre sócios, administradores e entre estes e a organização devem, preferencialmente, ser resolvidos mediante a negociação entre as partes. Caso isso não seja possível, recomenda-se que sejam resolvidos por meio de mediação e/ou arbitragem. É recomendável a inclusão desses mecanismos no estatuto/contrato social ou em compromisso a ser firmado entre as partes (IBGC, 2015, p. 27).

Assim, percebe-se que atualmente não só é permitida a utilização de cláusula arbitral nos contratos sociais, como é até recomendável essa inclusão, para que se obtenha uma melhor governança corporativa.

Além de ser muito interessante utilizar-se a cláusula arbitral para resolução de conflitos societários, é de suma importância que a cláusula seja cheia, ou, ao menos, administrativa, não sendo razoável constar uma cláusula arbitral vazia no contrato social.

Tal afirmativa é feita porque uma das principais vantagens teóricas da arbitragem é justamente a sua agilidade maior em comparação com os julgamentos ocorridos no âmbito do Poder Judiciário, o que decorre de diversos fatores, tais como, dentre outros, da especialização dos árbitros relativamente à matéria objeto da arbitragem, do prazo máximo para proferir a sentença arbitral (definido pelas partes ou estabelecida no art. 23 da Lei n. 9.307/96), da inexistência de recurso contra a sentença arbitral (conforme art. 18 da Lei n. 9.307/96). Caso seja inserida uma cláusula arbitral vazia no contrato e as partes não cheguem a um acordo, essa lacuna poderá ser dirimida por meio de um processo judicial, tornando o procedimento arbitral muito mais lento.

\section{DIREITO DE RECESSO}

O direito de recesso, também conhecido como direito de retirada, é assim conceituado por José Luís Bulhões Pedreira:

Direito de retirada é o poder do acionista de, nos casos previstos na LSA, deixar de ser sócio da companhia mediante formação, por ato unilateral, de negócio jurídico de reembolso, pelo qual aliena suas ações à companhia a dela recebe o valor de reembolso (BULHÕES PEDREIRA, 2017, p. 240).

Modesto Carvalhosa afirma, ainda, que "o exercício do direito de recesso, por constituir uma denúncia ou resilição unilateral e parcial, é negócio jurídico, produzindo a extinção da relação jurídica entre o acionista e a companhia" (CARVALHOSA, 1998, p. 743).

Não obstante, Fábio Ulhoa Coelho aponta que as hipóteses de recesso nas companhias são restritivas, pois:

Revista Brasileira de Direito Empresarial | e-ISSN: 2526-0235| Porto Alegre | v. 4 | n. 2 |

p. 58-78 | Jul/Dez. 2018 
$\mathrm{Na}$ sociedade anônima, a lei desestimula o desligamento do acionista por via do exercício do direito de recesso, ou retirada. Essa alternativa não se abre pela simples divergência em relação a qualquer decisão da assembleia geral. Aliás, ainda que importe alteração estatutária, a deliberação assemblear não justifica o recesso em todos os casos. Ao contrário, somente nas hipóteses especifica e expressamente contempladas na lei a discordância do acionista em relação ao deliberado pela maioria votante gera o direito de retirada (COELHO, 2010, p. 310-311).

No mesmo sentido, no âmbito das sociedades anônimas, Bulhões Pedreira aponta que "o regime legal do direito de retirada é cogente: o direito de retirada não pode ser restringido nem ampliado, quer pelo estatuto, quer pela Assembleia Geral" (BULHÕES PEDREIRA, 2017, p. 243).

A principal justificativa para essa taxatividade das hipóteses são decorres da proteção dos interesses da própria sociedade anônima, pois o exercício do direito de recesso pode gerar problemas para a sua sobrevivência, especialmente em decorrência do desembolso de valores normalmente significativos, necessários para o pagamento do valor de reembolso das ações dos dissidentes.

Por isso, Valverde, citado por Bulhões Pedreira, aponta que o instituto do direito de recesso tem uma dupla função: ao mesmo tempo que protege os acionistas minoritários, também protege a continuidade da empresa (apud BULHÕES PEDREIRA, 2017, p. 244).

Contudo, Rubens Requião traz uma questão muito importante sobre a deliberação para proteger a continuidade da empresa:

A decisão de recesso é muito grave. Pode, conforme o volume das ações dos dissidentes, levar a sociedade à descapitalização e à séria crise financeira. Daí porque a lei permite que a maioria volte atrás e cancele a deliberação que provocou a dissidência e o pedido de retirada dos acionistas (REQUIÃO, 2010, p. 225).

José Edwald Tavares Borba aponta, contudo, que esta retratação não foi prevista pelo Código Civil relativamente as sociedades limitadas (BORBA, 2015, p. 150). Contudo, é razoável sua aplicação, uma vez que a ideia de pacificação na sociedade é bem vista sob a perspectiva do princípio da preservação da empresa.

Nesse linha, Sérgio Mendes Botrel Coutinho traz à baila a interpretação do direito de recesso sob um viés constitucional, sob a perspectiva do direito de liberdade de associação, segundo o qual ninguém é obrigado a associar-se ou a manter-se associado. Assim, segundo o mencionado autor, o direito de recesso deve ser admitido em qualquer hipótese de existência de votos vencidos, e não somente nas hipóteses enumeradas expressamente na lei das sociedades anônimas, pois:

A partir do momento em que se admite a finalidade do direito privado é concretizar e/ou conciliar a realização dos direitos fundamentais, o direito de recesso há que ser 
interpretado como um mecanismo de concretização do direito fundamental de não permanecer associado (direito da livre associação) (BOTREL COUTINHO, 2009, p. 112).

Esse entendimento é seguido também por José Maria Rocha Filho, Gustavo Ribeiro Rocha (ROCHA FILHO; ROCHA, 2017, p. 403) e Marlon Tomazette (TOMAZETTE, 2011).

De acordo com esta visão, então, percebe-se que a limitação do direito de recesso ao rol descrito em artigos expressos na lei das sociedades anônimas não seria tão razoável. Em especial porque é possível se compatibilizar a possibilidade dada à Assembleia Geral de revogar seu posicionamento frente à quantidade de pedidos de exercício do direito de recesso com uma interpretação constitucional do direito societário, à luz do princípio de liberdade de associação (artigo $5^{\circ}, \mathrm{XX}$, da Constituição).

Todavia, como restou também demonstrado acima, nas sociedades anônimas, é possível admitir também que o direito de recesso é o direito que o sócio dissidente de uma deliberação de assembleia geral tem de deixar a sociedade, recebendo o valor de reembolso de suas ações, mas apenas nas hipóteses especificamente determinadas na lei. Ou seja, de acordo com essa perspectiva, não é qualquer dissidência que autoriza o acionista exercer o direito de retirada, mas apenas a dissidência relativa a um dos temas previstos de forma expressa na lei, geralmente relacionados com as bases teóricas essenciais da companhia, que justificaram a sua constituição e a sua existência.

Nas sociedades limitadas, todavia, em virtude do disposto no art. 1.077 do Código Civil, o direito de recesso pode ser mais amplo, independentemente de uma interpretação principiológica ou constitucional. Vejamos.

\subsection{DIREITO DE RECESSO NAS SOCIEDADES LIMITADAS}

Para os fins específicos desta pesquisa, é importante apontar que a lei que regula o direito de recesso dos sócios quotistas em uma sociedade limitada é o Código Civil, que, em seu artigo 1.077, estabelece o seguinte:

Art. 1.077. Quando houver modificação do contrato, fusão da sociedade, incorporação de outra, ou dela por outra, terá o sócio que dissentiu o direito de retirar-se da sociedade, nos trinta dias subsequentes à reunião, aplicando-se, no silêncio do contrato social antes vigente, o disposto no art. 1.031 (BRASIL, 2002).

De fato, existem inúmeras discussões possíveis relativamente a interpretação deste artigo 1.077 do Código Civil.

Revista Brasileira de Direito Empresarial | e-ISSN: 2526-0235| Porto Alegre | v. 4 | n. 2 |

p. 58-78 | Jul/Dez. 2018 
A primeira delas, diz respeito à amplitude do direito de recesso propriamente dito e, segundo ela, o direito de retirada somente é possível aos sócios das sociedades limitadas nos casos expressamente previstos no artigo 1.077 do Código Civil: mudança no contrato social, fusão e incorporação.

Ocorre, todavia, que, nas sociedades limitadas, as mudanças do contrato social podem ser relevantes, como a mudança do objeto social, a inclusão de novo sócio, a alteração do capital social e da participação dos sócios nos lucros e nas perdas, a modificação do administrador; ou teoricamente absolutamente irrelevantes, como a mudança do tipografia e/ou do tamanho das letras, a alteração da data do término do exercício social, a inclusão do endereço de uma filial.

Nesse sentido, segundo uma interpretação possível, qualquer mudança do contrato social, relevante ou não, atribui ao sócio dissidente o direito de retirada. Contudo, com fundamento no princípio da preservação da empresa, é possível também a defesa da interpretação segundo a qual somente as alterações relevantes do contrato social autorizam o exercício do direito de recesso dos sócios dissidentes, sobretudo quando, no caso concreto, o exercício do direito de retirada colocar em risco a continuidade da vida social e da manutenção da fonte empresarial produtiva.

Uma segunda interpretação controvertida acerca do direito de retirada e de sua amplitude nas limitadas, decorre da natureza hibrida dessas sociedades. De fato, dependendo do caso concreto, a sociedade limitada pode ser classificada como uma sociedade de pessoas, ou como uma sociedade de capitais. E mais: dependendo do disposto no contrato social, a sociedade pode ser regida supletivamente pelas normas relativas às sociedades simples ou pelas normas relativas às sociedades por ações.

Caso a regência supletiva da sociedade limitada seja pelas regras das sociedades simples, quando o contrato social é omisso acerca da regência supletiva, deve-se verificar se a sociedade possui prazo determinado ou indeterminado. Esta questão é importante porque, caso o prazo da sociedade seja indeterminado e esta seja regida supletivamente pelas normas previstas no Código Civil para as sociedades simples, o direito de retirada pode se confundir com uma hipótese de dissolução parcial da sociedade, que pode ser operacionalizada por meio de uma mera notificação do sócio que deseja sair para os demais sócios, nos termos do artigo 1.029 do Código Civil, que estabelece o seguinte:

Revista Brasileira de Direito Empresarial | e-ISSN: 2526-0235| Porto Alegre | v. 4 | n. 2 |

p. 58-78 | Jul/Dez. 2018 
Art. 1.029. Além dos casos previstos na lei ou no contrato, qualquer sócio pode retirar-se da sociedade; se de prazo indeterminado, mediante notificação aos demais sócios, com antecedência mínima de sessenta dias; se de prazo determinado, provando judicialmente justa causa.

Parágrafo único. Nos trinta dias subseqüentes à notificação, podem os demais sócios optar pela dissolução da sociedade (BRASIL, 2002).

Não há nesse caso, então, necessidade de o sócio dissidente justificar a sua decisão de deixar a sociedade, pois, segundo o princípio de liberdade de associação, previsto no artigo $5^{\circ}, \mathrm{XX}$, da Constituição, ninguém é obrigado a se associar ou a permanecer associado.

Especificamente sobre isso, Marlon Tomazette apresenta um posicionamento um pouco diferente e também discutível, no sentido de que se a sociedade limitada possuir prazo determinado, a aplicação seria restrita ao conteúdo descrito no artigo 1.077 do Código Civil uma vez que as partes se comprometeram já sabendo o tempo que estariam vinculados à sociedade e aos demais sócios, apenas sendo razoável o exercício do direito de recesso em caso de quebra de legítima expectativa dos sócios (TOMAZETTE, 2011, p. 222-223).

No entanto, se o contrato social prever de forma expressa a regência supletiva da sociedade limitada pelas normas das sociedades anônimas, o direito de recesso pode acontecer tanto em virtude dos casos específicos determinados no artigo 1.077 do Código Civil, quanto em decorrência da aplicação supletiva de outras hipóteses específicas de recesso previstas na Lei n. 6.404/76 (artigos 136-A, 137, 221, 223, 252, dentre outros).

\section{DIREITO DE RECESSO DECORRENTE DA INCLUSÃo DE CLÁUSULA COMPROMISSÓRIA EM CONTRATO SOCIAL DE SOCIEDADE LIMITADA}

Relativamente à instituição da arbitragem nos contratos em geral, e nos contratos de adesão em particular, a Lei n. 9.307/96 estabelece o seguinte:

\footnotetext{
Art. $4^{\circ}$ A cláusula compromissória é a convenção através da qual as partes em um contrato comprometem-se a submeter à arbitragem os litígios que possam vir a surgir, relativamente a tal contrato.

$\S 1^{\circ}$ A cláusula compromissória deve ser estipulada por escrito, podendo estar inserta no próprio contrato ou em documento apartado que a ele se refira.

$\S 2^{\circ}$ Nos contratos de adesão, a cláusula compromissória só terá eficácia se o aderente tomar a iniciativa de instituir a arbitragem ou concordar, expressamente, com a sua instituição, desde que por escrito em documento anexo ou em negrito, com a assinatura ou visto especialmente para essa cláusula (BRASIL, 1996).
}

Revista Brasileira de Direito Empresarial | e-ISSN: 2526-0235| Porto Alegre | v. 4 | n. 2 |

p. 58-78 | Jul/Dez. 2018 
Todavia, o tratamento atribuído pela Lei de Arbitragem para os contratos de adesão não pode ser aplicado aos contratos sociais, uma vez que existe diferença sensível entres os dois institutos.

Nesse sentido, de acordo com Luís Loria Flaks:

\begin{abstract}
[...] o contrato de adesão se caracteriza, em regra, pela bilateralidade da relação jurídica, ou seja, pela existência de interesses distintos das partes contratantes, diferentemente do que acontece em uma sociedade.

Ocorre que os interesses dos acionistas de uma companhia, independentemente de seu objeto social, convergem necessariamente para um mesmo fim: a obtenção de lucro pela sociedade. Essa convergência de interesses é uma das principais características dos chamados contratos plurilaterais - como são os estatutos sociais - os quais, de modo algum, poderiam ser considerados como contratos de adesão (FLAKS, 2003, p.103).
\end{abstract}

Percebe-se, então, que a convergência de interesses nos contratos plurilaterais, tais como os contratos sociais, os diferencia totalmente da maioria dos contratos de adesão, nos quais os interesses dos sócios normalmente são antagônicos e não paralelos, como ocorre, em regra, nos contratos e estatutos sociais.

Por isso, nos contratos sociais, a eficácia da inserção de uma cláusula compromissória não fica condicionada à deliberação unânime dos sócios, ou ao cumprimento de requisitos formais específicos, como o uso de letras em negrito, a assinatura ou o visto dos sócios relativamente a essa cláusula.

De fato, para que uma sociedade tenha a sua "vontade" estabelecida, os sócios devem deliberar e votar para saber qual será a posição tomada pela sociedade, observados os limites estabelecidos pelo contrato/estatuto social e pela própria legislação de regência da sociedade em questão. Por isso, dependendo do caso concreto, algumas deliberações sociais exigem, para sua aprovação, a maioria simples, outras a maioria qualificada e, excepcionalmente, em situações muito específicas, até a totalidade dos votos.

A vontade social, então, em regra, depende do resultado das deliberações dos sócios. E o resultado obtido por meio de reunião ou de assembleia dos sócios, afeta tanto aqueles que votaram favoravelmente, quanto aqueles que votaram em outro sentido, como também aqueles que não compareceram.

A legitimação de uma decisão política (tomada em um órgão deliberativo que afeta os demais componentes de uma sociedade) é bem explicada por Bernard Manin, que aponta que uma decisão é legítima quando respeitada a deliberação de todos e não a vontade de todos (MANIN, 2007, p. 31). 
Faz parte da democracia em uma sociedade que possui diferentes pensamentos que as pessoas que possuam votos vencidos se submetam à vontade da maioria, desde que tal vontade tenha sido discutida de forma sistêmica e não tenha como interesse direto prejudicar o grupo minoritário.

A única ressalva que pode ser feita relativamente às deliberações sociais é que algumas, determinadas expressamente na lei, atribuem aos dissidentes o direito de retirada (ou de recesso) da sociedade, recebendo os dissidentes, caso a deliberação seja ratificada após o término do prazo determinado para o exercício desse direito, o valor de reembolso de suas quotas/ações.

Especificamente em relação às sociedades anônimas, a Lei $\mathrm{n}^{\circ}$. 13.129/2015 alterou o texto da Lei n. 6.404/76, e introduziu na mesma o artigo 136-A, que estabelece o seguinte:

Art. 136-A. A aprovação da inserção de convenção de arbitragem no estatuto social, observado o quórum do art. 136, obriga a todos os acionistas, assegurado ao acionista dissidente o direito de retirar-se da companhia mediante o reembolso do valor de suas ações, nos termos do art. 45.

§ 1ำ A convenção somente terá eficácia após o decurso do prazo de 30 (trinta) dias, contado da publicação da ata da assembleia geral que a aprovou.

$\S 2$ o $\mathrm{O}$ direito de retirada previsto no caput não será aplicável:

I - caso a inclusão da convenção de arbitragem no estatuto social represente condição para que os valores mobiliários de emissão da companhia sejam admitidos à negociação em segmento de listagem de bolsa de valores ou de mercado de balcão organizado que exija dispersão acionária mínima de $25 \%$ (vinte e cinco por cento) das ações de cada espécie ou classe;

II - caso a inclusão da convenção de arbitragem seja efetuada no estatuto social de companhia aberta cujas ações sejam dotadas de liquidez e dispersão no mercado, nos termos das alíneas "a" e "b" do inciso II do art. 137 desta Lei (BRASIL, 1976).

Verifica-se, portanto, que atualmente a lei das sociedades por ações permite expressamente a inclusão de cláusula arbitral ou compromissória no estatuto social dessas sociedades, mas garante ao sócio dissidente exercer o direito de recesso quando ele discorda desse tipo de alteração estatutária.

Contudo, no caso específico da sociedade limitada, não há nenhuma norma que proíba a inclusão de uma cláusula compromissória no contrato social. Assim, em virtude do princípio da autonomia da vontade, os sócios podem livremente deliberar acerca da inclusão de uma cláusula de arbitragem no contrato social da sociedade limitada. 
Além disso, em princípio, em virtude do disposto no artigo 1.077 do Código Civil, não existe previsão expressa para o exercício do direito de retirada para o sócio dissidente da inserção de cláusula compromissória em um contrato social desse tipo jurídico de sociedade.

Todavia, uma vez modificado o contrato social da limitada para se determinar a inclusão de cláusula arbitral, o sócio que não estiver de acordo com esta decisão pode exercer seu direito de recesso, com dois ou três fundamentos juridicamente defensáveis.

Primeiro, com fundamento no disposto no próprio artigo 1.077 do Código Civil, pois a inserção de cláusula compromissória no contrato social antes vigente, implica alteração significativa do contrato social, uma vez que, na prática, as eventuais controvérsias societárias serão dirimidas por meio de arbitragem e não por intermédio da jurisdição estatal. E isso, inclusive, pode determinar a escolha de uma legislação específica, bem como a determinação dos árbitros ou da instituição responsável pelo procedimento, além da distribuição diferenciada dos custos do procedimento entre os sócios, com a possibilidade de serem afetados importantes direitos dos sócios não controladores (minoritários).

Segundo, mesmo que não se admita o recesso dos dissidentes em virtude do disposto no artigo 1.077 do Código Civil (porque esse dispositivo não prevê expressamente a inserção de cláusula compromissória como motivo para o exercício do direito de retirada), esse direito poderá ser exercício, nas sociedades limitadas regidas supletivamente pelas normas das sociedades simples, com fundamento no disposto no princípio constitucional de liberdade de associação (artigo $5^{\circ}$, inciso XX, da Constituição da República), combinado com o disposto no no artigo 1.029 do Código Civil.

Em terceiro lugar, nas sociedades limitadas regidas supletivamente pelas normas das sociedades anônimas, o direito de retirada dos sócios dissidentes da inserção da cláusula compromissória pode ser possível, com fundamento no disposto no artigo 136-A, da Lei n. 6.404/76, que o prevê expressamente.

\section{CONCLUSÃO}

Em virtude da pesquisa realizada, pode-se concluir que o ordenamento jurídico brasileiro, a partir do disposto na Constituição da República e nas demais normas existentes, válidas e eficazes no sistema normativo, aproxima-se muito do paradigma pós-positivista, que reconhece a incompletude do sistema legal e, por isso, a multiplicidade das fontes do direito,

Revista Brasileira de Direito Empresarial | e-ISSN: 2526-0235| Porto Alegre | v. 4 | n. 2 |

p. 58-78 | Jul/Dez. 2018 
bem como que as normas jurídicas (gênero), podem assumir características de princípios (fundamentais, gerais e específicos) ou de regras, mas sempre com caráter normativo, para determinar a estruturação jurídica dos objetivos das pessoas ou a solução de eventuais conflitos decorrentes das relações interpessoais e jurídicas.

Nesse sentido, de acordo com o princípio da normatividade (que constitui evolução pós-positivista do princípio da legalidade estrita), ninguém é obrigado a fazer ou deixar de fazer alguma coisa, senão em virtude de norma jurídica (princípio ou regra) existente, válida, eficaz e estabelecida pelas diversas e múltiplas fontes do direito - formais ou não formais, tais como: constituição, leis, jurisprudência, costumes, contratos, atos administrativos, doutrina.

Ademais, especificamente em matéria de direito empresarial societário, em virtude do princípio da autonomia privada, tudo aquilo que não é proibido é permitido.

De fato, a Lei n. 9.307/96 permite que as controvérsias relativas aos direitos patrimoniais disponíveis, tais como os direitos geralmente abrangidos por um contrato ou estatuto social, possam ser dirimidas por meio da arbitragem, desde que exista uma cláusula compromissória, ou desde que seja celebrado um compromisso arbitral pelas partes.

Realmente, como restou demonstrado, não há nenhuma norma legal que proíba a inclusão de cláusulas arbitrais nos contratos sociais das sociedades limitadas, mesmo após a constituição dessas sociedades.

Todavia, seja nas sociedades limitadas regidas supletivamente pelas normas das sociedades simples, seja nas limitadas regidas supletivamente pelas normas das sociedade anônimas, o sócio dissidente da inserção de cláusula compromissória no contrato social tem o direito de retirada (recesso), bem como de receber o valor de reembolso de suas quotas, tal como previsto no contrato social e/ou na lei.

\section{REFERÊNCIAS}

ALEXY, Robert. Teoria discursiva do direito. organização, tradução e estudo introdutório: Alexandre Travessoni Gomes Trivisonno. 1. ed. Rio de Janeiro: Forense Universitária, 2014.

BOBBIO, Norberto. Teoria da norma jurídica. 2. ed. Revista. Bauru: EDIPRO, 2003.

BORBA, José Edwaldo Tavares. Direito Societário. 14. ed. São Paulo: Atlas, 2015. 
BOTREL COUTINHO, Sérgio Mendes. Direito societário constitucional. São Paulo: Saraiva, 2009

BRASIL. Constituição da República Federativa do Brasil de 1988. Diário Oficial da União, Brasília, 05 de outubro de 1988.

BRASIL. Lei 6.404, de 15 de dezembro de 1976. Dispõe sobre as Sociedades por Ações. Diário Oficial da União, Brasília, 17 de dezembro de 1976.

BRASIL. Lei 9.307, de 23 de setembro de 1996. Dispõe sobre a arbitragem. Diário Oficial da União, Brasília, 24 de setembro de 1996.

BRASIL. Lei 10.406, de 10 de janeiro de 2002. Institui o Código Civil. Diário Oficial da União, Brasília, 10 de janeiro de 2002.

BULGARELLI, Waldírio. Normas jurídicas empresariais. São Paulo: Atlas, 1992.

BULHÕES PEDREIRA, José Luís. Direito de Retidada. In: BULHÕES PEDREIRA, José Luis; LAMY FILHO, Alfredo (coord). Direito das companhias. 2. Ed. Rio de Janeiro: Forense, 2017.

CARMONA, Carlos Alberto. Arbitragem e processo: um comentário à Lei 9.307/96. 2. ed. São Paulo: Atlas, 2004.

CARVALHOSA, Modesto. Comentários à Lei de Sociedades Anônimas. 2. ed. São Paulo: Saraiva, 1998, V. II.

COELHO, Fábio Ulhoa. Curso de direito comercial: direito de empresa. 14. ed. São Paulo: Saraiva, 2010, V. II.

COULANGES, Fustel de. A cidade antiga. Tradução Frederico Ozanam Pessoa de Barros em 2006. Disponível em: < http://bibliotecadgital.puc-campinas.edu.br/services/ebooks/Fustel\%20de\%20Coulanges-1.pdf > . Acesso em: 27 nov. 2017.

DWORKIN, Ronald. Levando os Direitos a sério. Trad. Nelson Boeira. São Paulo: Martins Fontes. 2002.

FLAKS, Luís Loria. A arbitragem na reforma da Lei das S/A. Revista de Direito Mercantil Industrial, Econômico e Financeiro, Ano XLII, p. 100-121, Jul-Set, 2003. Disponível em: $<$ http://bmalaw.com.br/arquivos/Artigos/A_ARBITRAGEM_NA_REFORMA_DA_LEI_DA S_S_A_.pdf $>$. Acesso em 09 de dezembro de 2017.

FREITAS, Sérgio Henriques Zandona; MOREIRA, Felipe Bartolomeo. Apontamentos sobre teorias da argumentação jurídica na história do direito. In: Seminário nacional de formação de pesquisadores e iniciação científica em direito da FEPODI, 2017, Belo Horizonte. Seminário nacional de formação de pesquisadores e iniciação científica em direito da FEPODI. Florianópolis: CONPEDI, 2016. v. 1. p. 1687-1694. 
GABRICH, Frederico de Andrade. Análise Estratégica do Direito. In: GABRICH, Frederico de Andrade (Org.). Análise Estratégica do Direito. Belo Horizonte: Universidade FUMEC Faculdade de Ciências Humanas e Sociais, 2010, p. 09-32.

GOMES, Orlando. Transformações gerais do direito das obrigações. São Paulo: RT, 1967.

INSTITUTO BRASILEIRO DE GOVERNANÇA CORPORATIVA. Código das melhores práticas de governança corporativa. 5. ed, São Paulo: IBGC, 2015.

HABERMAS, Jürgen. Direito e democracia: entre facticidade e validade. Trad. Flávio Beno Siebeneichler. Rio de Janeiro: Tempo Brasileiro, 1997, t. I e II.

KELSEN, Hans. Teoria pura do direito. 3. ed. São Paulo: Martins Fontes, 1991.

MAKANT, Barbara. A arbitragem nas sociedades empresárias. In: FONSECA, Rodrigo Garcia da; WALD, Arnoldo (Org.). A empresa no terceiro milênio: Aspectos jurídicos. São Paulo: Juarez de Oliveira, 2005, p. 575-603.

MANIN, Bernard. Legitimidade e Deliberação Política. In: WERLE, Denílson Luiz. E MELO, Rúrion Soares (Org.). Democracia Deliberativa. São Paulo: Singular, Esfera Pública, 2007, p.15-45.

MÜLLER, Friedrich. Discours de la méthode juridique. Paris, PUF, 1996

NADER, Paulo. Introdução ao estudo do direito. 36. ed. Rio de Janeiro: Forense, 2014.

REQUIÃO, Rubens. Curso de direito comercial. 27. ed. São Paulo: Saraiva, 2010, V, II.

ROCHA FILHO, José Maria; ROCHA, Gustavo Ribeiro. Curso de direito comercial: Teoria geral da empresa, direito societário e títulos de crédito. 4. ed. Belo Horizonte: D’Plácido, 2017.

SCAVONE JR., Luiz Antonio. Manual de Arbitragem - Mediação e Conciliação. São Paulo: Editora Forense (Edição do Kindle), 2018.

TOMAZETTE, Marlon. Liberdade de associação e o recesso nas sociedades limitadas.

Revista de Direito Brasileira. V.1, n. 1, p 209-228, 2011. Disponível em:

<http://www.rdb.org.br/ojs/index.php/rdb/article/viewFile/58/57>. Acesso em: $10 \mathrm{dez} 2017$.

TRAVESSONI GOMES, Alexandre. Kant e o pós-positivismo no direito. In: TRAVESSONI GOMES, Alexandre; MERLE Jean-Christophe. A Moral e o Direito em Kant - ensaios analíticos. Belo Horizonte: Mandamentos, 2007. 